\title{
Video-assisted thoracoscopic surgery for primary lung cancer resections in patients with moderate to severe chronic obstructive pulmonary diseases
}

\author{
Ke Xu${ }^{\#} \wedge$, Weipeng Cai", Yuan Zeng, Jingpei Li, Jianxing He, Fei Cui, Jun Liu \\ Department of Thoracic Surgery, The First Affiliated Hospital of Guangzhou Medical University, State Key Laboratory of Respiratory Disease, \\ National Clinical Research Center for Respiratory Disease, Guangzhou Institute of Respiratory Health, Guangzhou, China \\ Contributions: (I) Conception and design: K Xu, F Cui, J Liu; (II) Administrative support: J He; (III) Provision of study materials or patients: Y Zeng, \\ J Li, F Cui, J Liu; (IV) Collection and assembly of data: K Xu, W Cai; (V) Data analysis and interpretation: K Xu, W Cai; (VI) Manuscript writing: \\ All authors; (VII) Final approval of manuscript: All authors. \\ \#These authors contributed equally to this work. \\ Correspondence to: Dr. Fei Cui; Prof. Jun Liu. Department of Thoracic Surgery, The First Affiliated Hospital of Guangzhou Medical University, State \\ Key Laboratory of Respiratory Disease, National Clinical Research Center for Respiratory Disease, Guangzhou Institute of Respiratory Health, \\ Guangzhou, China. Email: cuidavil@hotmail.com; liujun9707@sina.com.
}

Background: Lung cancer patients with chronic obstructive pulmonary disease (COPD) are considered a high-risk population to receive radical surgical treatment due to the high incidence of cardiopulmonary complications. The aim of this study was to evaluate the clinical factors associated with postoperative complications in primary lung cancer patients with moderate to extremely severe grades of COPD.

Methods: From December 2015 to June 2020, 138 patients with moderate to extremely severe COPD who underwent video-assisted thoracoscopic surgery (VATS) lung cancer resection (lobectomy or sublobar resection) were retrospectively reviewed. Patients' postoperative complications were collected from clinical records. Clinical factors (such as COPD severity or surgical approaches, etc.) were evaluated to investigate the association with postoperative complications.

Results: Of the 138 patients included in the study, the mean age was 67 (63-74) years, the mean preoperative forced expiratory volume in one second (FEV1) was $1.33 \pm 0.39 \mathrm{~L}$, the mean FEV $1 \%$ was $51.23 \%$ (41.43-60.00\%). 33\% patients (46/138) had postoperative complications, and no mortality occurred. Univariate analysis revealed that incidence of overall complications (OCs) and respiratory complications (RCs) was markedly higher in extremely severe COPD patients compared to moderate (OCs, $\mathrm{P}=0.033$; $\mathrm{RCs}, \mathrm{P}=0.050)$ and severe (OCs, $\mathrm{P}=0.015$; $\mathrm{RCs}, \mathrm{P}=0.008)$ COPD patients, respectively. Multivariate analysis showed that $\mathrm{COPD}$ grade was an independent risk factor of $\mathrm{RCs}(\mathrm{P}=0.024)$. Furthermore, the grades of COPD (moderate, $\mathrm{P}=0.029$; severe, $\mathrm{P}=0.028$; extremely severe, $\mathrm{P}=0.019$ ) and the surgical procedure (lobectomy or sublobar resection, $\mathrm{P}=0.043$ ) were independent risk factors for atelectasis, which was the most common postoperative complication.

Conclusions: The aggravation of COPD was accompanied by an increase in the incidence of respiratory system complications postoperatively, especially atelectasis. For patients with moderate to extremely severe grades of COPD, careful perioperative evaluation should be performed to identify the indicators that influence the surgical choice between lobectomy and sublobar resection.

Keywords: Chronic obstructive pulmonary disease (COPD); lung cancer; complications; surgery

Submitted Sep 24, 2020. Accepted for publication Jun 17, 2021.

doi: $10.21037 /$ tlcr-21-449

View this article at: https://dx.doi.org/10.21037/tlcr-21-449

\footnotetext{
$\wedge$ ORCID: 0000-0002-6259-5244.
} 


\section{Introduction}

Lung cancer is the leading causes of death worldwide (1). Chronic obstructive pulmonary disease (COPD) is characterized by persistent airflow limitation that lead to destruction of lung tissue and the long-term decline in lung function (2). Due to a chronic systemic, local inflammatory state and lung tissue remodeling, COPD patients have an increased risk of lung cancer (3). The incidence of lung cancer in COPD patients in the United States is as high as $16.7 / 1,000$ cases per year (4). For these special subgroups of patients with co-occurring COPD and lung canceroften referred to as severe lung cancer (5)—standardized inhalation therapy along with antitumor therapy may improve the quality of life and prognosis (6).

Although surgical resection is still the treatment of choice for patients with severe lung cancer, reduced lung function and insufficient respiratory reserve make these patients face a higher risk of surgery. The published standard indicators of inoperability include: baseline forced expiratory volume in 1 second (FEV1) less than $40 \%$ predicted, postoperative FEV1 less than $30 \%$ predicted, carbon monoxide diffusing capacity (DLCO) less than $40 \%$ predicted, baseline hypoxemia or hypercapnia, and severe pulmonary hypertension (7). The severity of COPD limits surgical options and treatment opportunities because of the limited lung function and cardiopulmonary complications (8).

The latest advances in video-assisted thoracic surgery (VATS) have reduced surgery-related morbidity and mortality in patients with non-small cell lung cancer (NSCLC) (9). Minimally invasive surgical techniques may have a substantial beneficial impact on the ability of patients with COPD to tolerate surgery. The purpose of this study is to analyze the clinical characteristics associated with postoperative complications in COPD patients undergoing VATS for primary lung cancer, and to explore the criteria that influence the choice of surgery between lobectomy and sublobar resection. We present the following article in accordance with the STROBE reporting checklist (available at https://dx.doi.org/10.21037/tlcr-21-449).

\section{Methods}

\section{Setting and participants}

The study recruited patients with COPD and newly diagnosed lung cancer who were hospitalized in the First Affiliated Hospital of Guangzhou Medical University. Between December 2015 and June 2020, NSCLC patients diagnosed with moderate to extremely severe COPD according to the Global Guidelines for the Diagnosis and Treatment of COPD were enrolled in the study. The criteria for determining COPD severity were based on the following Global Initiative for Chronic Obstructive Lung Disease (GOLD) classification standard of COPD: moderate $=\mathrm{FEV} 1 /$ forced vital capacity $(\mathrm{FVC}) \leq 70 \%$ and $50 \% \leq \mathrm{FEV} 1<80 \%$ predicted; severe COPD $=\mathrm{FEV} 1 / \mathrm{FVC}$ $\leq 70 \%$ and $30 \% \leq \mathrm{FEV} 1<50 \%$ predicted; extremely severe $\mathrm{COPD}=\mathrm{FEV} 1 / \mathrm{FVC} \leq 70 \%$ and $\mathrm{FEV} 1<30 \%$.

\section{Study design}

This observational cross-sectional design was used to allow for complications estimation. The data were prospectively collected using a structured study data sheet. The study was approved by the ethics committee of the First Affiliated Hospital of Guangzhou Medical University (18-041/1616). The requirement for informed consent from each patient was waived due to the retrospective nature of this analysis. According to the anatomical location and staging defined by the International Union for Cancer Control (UICC) guidelines (2007), all tumors were considered operable. All patients received at least 1 week of standardized COPD treatments, including medication and physical therapy to improve lung function. All patients were intubated with double-lumen endotracheal intubation. The patients were managed with antibiotics, bronchial relaxants, antispasmodics, phlegm-reducing techniques, oxygen therapy and physical sputum excretion after surgery. Those with poor sputum expectoration were treated with bronchoscopy, and those with respiratory failure were treated with mechanical ventilation.

\section{Outcome definition}

Intraoperative complications include injuries to blood vessels, nerves and other tissues and organs, and intraoperative bleeding that requires blood transfusion. Postoperative complications include: (I) cardiac complications (CCs) (congestive heart failure, myocardial infarction, arrhythmia and pulmonary edema, etc.); (II) respiratory complications (RCs) (pneumonia, atelectasis, pleural effusion or breathing (Machine); (III) venous thromboembolism events [deep vein thrombosis (DVT) or pulmonary embolism]; (IV) bleeding that requires blood transfusion or blood products; (V) infections other than pneumonia (wound infection or abscess); and (VI) re- 
admission due to surgical complications or reoperation. Data on preoperative lung function tests, operation duration, duration of indwelling chest tube, and length of hospital stay were also collected. All procedures performed in this study involving human participants were in accordance with the Declaration of Helsinki (as revised in 2013).

\section{Statistical analysis}

The Kolmogorov-Smirnov test is used to check the distribution of measured data. Continuous variables with normal distribution are expressed as mean \pm standard deviation and $95 \%$ confidence interval, and independent sample $t$ test is used. Categorical variables are expressed as frequencies and percentages, using the $\chi^{2}$ test. The chi-square test or Fisher's exact test (as the case may be) was used to test the predictive factors of postoperative complications (demographics, comorbidities, surgery, etc.) on the categorical data and Student $t$-test or Mann-Whitney $\mathrm{U}$ test [as the case may be (history and surgical procedures)] for continuous data. A multiple logistic regression model with stepwise forward elimination was used to evaluate the independent associations between potential predictors and complications. This study used a two-sided test level, $\mathrm{P}<0.05$ considered the difference to be statistically significant. All statistical analyses were performed using SPSS statistical software (version 19.0; IBM SPSS, Armonk, New York, USA), and graphs were analyzed using GraphPad Prism software (version 7.0; GraphPad Software, San Diego, California, USA).

\section{Results}

\section{Baseline clinical data characteristics}

From December 2015 to June 2020, a total of 1084 patients with ASA scores of III-IV and undergoing surgery were reviewed from the database, of which 175 were diagnosed as primary lung cancer with moderate - extremely severe COPD. Among of them, 37 patients with missing data of pulmonary function tests or no available records of complication event were excluded. Finally, 138 patients were included in the current analysis, including 118 men (86\%) and 20 women (14\%), the flow diagram of patients' selection was shown in Figure S1. The baseline characteristics of the patients are summarized in Table 1 . The mean age was 67 years (63-74 years). Seventy-seven patients were long-
Table 1 Baseline characteristics of the enrolled primary lung cancer patients with COPD

\begin{tabular}{|c|c|}
\hline Characteristics & $\mathrm{N}[\%]$ \\
\hline Total & 138 \\
\hline \multicolumn{2}{|l|}{ Age (years) } \\
\hline$<68$ & $65[47]$ \\
\hline$\geq 68$ & 73 [53] \\
\hline Mean $( \pm \mathrm{SD})$ & $67.61 \pm 8.406$ \\
\hline \multicolumn{2}{|l|}{ Smoking status } \\
\hline Nonsmoker & 59 [43] \\
\hline Former smoker & 34 [25] \\
\hline Current smoker & $43[32]$ \\
\hline \multicolumn{2}{|l|}{ Gender } \\
\hline Male & $118[86]$ \\
\hline Female & $20[14]$ \\
\hline \multicolumn{2}{|l|}{ Past medical history } \\
\hline Hypertension & $51[37]$ \\
\hline Diabetes type II & 19 [14] \\
\hline Coronary heart disease & $15[11]$ \\
\hline Tuberculosis & $7[5]$ \\
\hline Asthma & $10[7]$ \\
\hline Chronic renal insufficiency & $7[5]$ \\
\hline Arrhythmia & $3[2[$ \\
\hline Cerebral infarction & $8[6]$ \\
\hline \multicolumn{2}{|l|}{ COPD GOLD stages } \\
\hline Moderate & $83[60]$ \\
\hline Severe & 40 [29] \\
\hline Extremely severe & $15[11]$ \\
\hline \multicolumn{2}{|c|}{ Preoperative pulmonary function indexes } \\
\hline FEV1 (L) & $1.33 \pm 0.39$ \\
\hline FEV1\% & $51.23(41.43-60.00)$ \\
\hline FVC (L) & $2.45 \pm 0.66$ \\
\hline FVC\% & $72.25(70.02-75.18)$ \\
\hline \multicolumn{2}{|l|}{ Tumor location } \\
\hline Upper lobe & $81[59]$ \\
\hline Middle lobe & $11[8]$ \\
\hline Lower lobe & $46[33]$ \\
\hline
\end{tabular}

Table 1 (continued) 
Table 1 (continued)

\begin{tabular}{|c|c|}
\hline Characteristics & $\mathrm{N}[\%]$ \\
\hline \multicolumn{2}{|l|}{ Surgical procedures } \\
\hline Lobectomy & $72[52]$ \\
\hline Sublobar resections & $66[48]$ \\
\hline \multicolumn{2}{|l|}{ Overall surgical time (min) } \\
\hline Mean $( \pm$ SD) & $147.55 \pm 77.12$ \\
\hline \multicolumn{2}{|l|}{ Overall anesthesia time (min) } \\
\hline Mean $( \pm \mathrm{SD})$ & $231.40 \pm 93.24$ \\
\hline \multicolumn{2}{|l|}{ Intraoperative bleeding (mL) } \\
\hline Mean $(25-75 \%)$ & $111.38(20-100)$ \\
\hline \multicolumn{2}{|l|}{ Intraoperative complications } \\
\hline Steady & $136[98.6]$ \\
\hline Hemorrhagic shock & $1[0.7]$ \\
\hline Atrial fibrillation & $1[0.7]$ \\
\hline \multicolumn{2}{|l|}{ Histology } \\
\hline Squamous cell & $45[33]$ \\
\hline Adenocarcinoma & $82[59]$ \\
\hline Other types & $11[8]$ \\
\hline \multicolumn{2}{|l|}{ TNM stages ( $8^{\text {th }}$ Edition) } \\
\hline IA & $67[49]$ \\
\hline IB & 30 [22] \\
\hline$\| \mathrm{A}$ & $14[10]$ \\
\hline IIB & $6[4]$ \\
\hline IIIA & 17 [12] \\
\hline IIIB & $4[3]$ \\
\hline \multicolumn{2}{|l|}{ Respiratory rehabilitation interventions } \\
\hline BiPAP-assisted ventilation & $43[31]$ \\
\hline $\begin{array}{l}\text { Sputum suction via fiberoptic broncho- } \\
\text { scope }\end{array}$ & 18 [13] \\
\hline \multicolumn{2}{|l|}{ Lengths of stay (d) } \\
\hline Mean ( \pm SD) & $7.99 \pm 4.78$ \\
\hline \multicolumn{2}{|l|}{ Volume of drainage $(\mathrm{mL})$} \\
\hline Mean $( \pm \mathrm{SD})$ & 914.06 \\
\hline
\end{tabular}

COPD, chronic obstructed pulmonary diseases; GOLD, Global Initiative for Chronic Obstructive Lung Disease; FEV1, forced expiratory volume in one second; FVC, forced vital capacity; TMN, tumor-node-metastasis; BiPAP, bilevel positive airway pressure. term smokers. The preoperative FEV1/FVC was $69.9 \%$, and $60 \%(83 / 138)$ of patients were categorized as moderate stage, $30 \%(40 / 138)$ were categorized as severe, and $11 \%$ $(15 / 138)$ were categorized as extremely severe. The mean preoperative FEV1 was $1.33 \mathrm{~L}(\mathrm{SD}=0.39)$, and the mean FEV1\% was $51.23 \%$ (41.43-60.00\%). Among them, 97 cases were stage I, 20 cases were stage II, and 21 cases were stage IIIA. None patient had significant contraindications, such as cardiovascular, digestive, urinary, endocrine, or other systemic diseases.

\section{Operative situations}

Regarding to the surgical approaches, $52 \%$ patients (72/138) received VATS lobectomy with systematic lymph node dissections, and $48 \%$ patients $(66 / 138)$ received VATS sublobar resections (included wedge resections or segmentectomy) with lymph node dissections, both under general mechanical ventilation anesthesia. The majority of procedures were uneventful; only 1 patient suffered hemorrhagic shock caused by unexpected heavy bleeding due to extensive chest adhesion. Another patient had atrial fibrillation intraoperatively and was given amiodarone for cardioversion. No mortality occurred during the surgery (Table 1).

\section{Postoperative complications}

For the primary outcome, $33 \%$ of patients (46/138) presented with postoperative complications. More specifically, $28 \%$ of patients (39/138) had respiratory system complications, and $9 \%$ of patients $(13 / 138)$ had cardiac system complications (Figure 1). Of these, postoperative air leak and atelectasis were reported in $9 \%$ of patients (13/138), which was the most common postoperative adverse event in this cohort and was managed by prolonged ( $>7$ days) chest tube drainage and supportive treatments. Furthermore, $8 \%$ of patients $(11 / 138)$ were found to have aggravated pulmonary infection, which was treated with upgraded antibiotics; and $7 \%$ of patients (9/138) had pleural effusion postoperatively, which was treated with extra thoracentesis to drain excess fluid from the pleural cavity. For other postoperative complications, $3 \%$ of patients (4/138) were diagnosed with type II respiratory failure and $1.5 \%$ patients $(2 / 138)$ with chylothorax. In total, $31 \%$ of patients $(43 / 138)$ had poor conditions of pulmonary ventilation postoperatively and needed to receive bilevel positive airway pressure (BiPAP) mode noninvasive mechanical ventilation, 


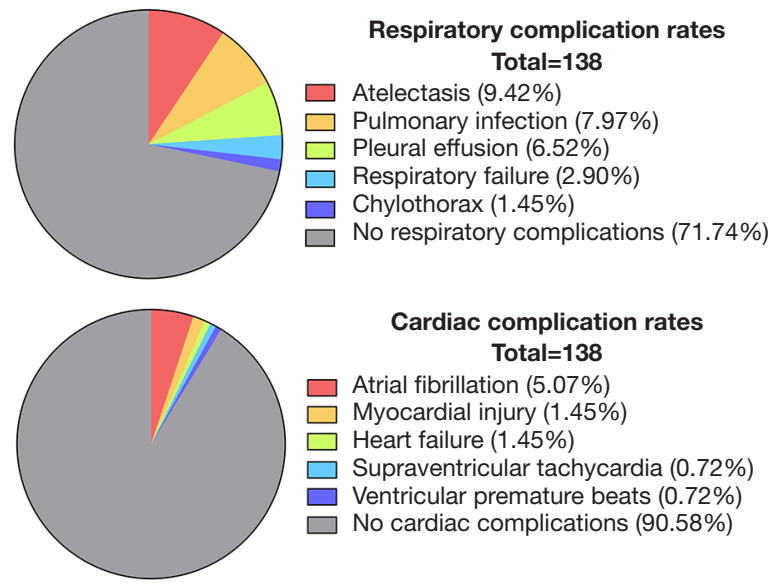

Figure 1 The postoperative complication rates in primary lung cancer patients with moderate to extremely severe COPD. COPD, chronic obstructed pulmonary diseases.

while $13 \%$ of patients $(18 / 138)$ received sputum suction via fiberoptic bronchoscope (Table 1). However, seven patients still required further mechanical ventilation under nasal or oral endotracheal intubation, and all these patients were successfully weaned, ultimately without any assisted ventilation.

Next, the univariate analysis of the overall complications (OCs), respiratory or cardiac system complications stratified by clinical characteristics was conducted (Table 2). We found that GOLD stages showed statistically significant correlations with $\mathrm{OC}$ rate $(\mathrm{P}=0.044)$ and $\mathrm{RC}$ rate $(\mathrm{P}=0.03)$. Moreover, significantly frequent $\mathrm{OC}$ rates occurred in extremely severe COPD patients compared to moderate [odds ratio $(\mathrm{OR})=4.550, \mathrm{P}=0.033)$ and severe grade $(\mathrm{OR}$ $=5.910, \mathrm{P}=0.015) \mathrm{COPD}$ patients. Similarly, significant higher $\mathrm{RC}$ rates were observed in extremely severe COPD patients compared to the moderate $(\mathrm{OR}=3.857, \mathrm{P}=0.050)$ and severe grade $(\mathrm{OR}=7.062, \mathrm{P}=0.008)$ subgroups (Figure 2$)$. However, we did not note significant differences in the incidence of any complication categories in terms of gender, age, smoking history, pathological stages based on the eighth tumor-node-metastasis (TNM) staging system, tumor location, or surgical approach (lobectomy vs sublobar resection) (Table 2). Furthermore, in multivariate analysis, the COPD grades were not independent risk factors for the incidence of OCs but were strongly associated with RCs $(\mathrm{P}=0.024)$ (Table 3).

Furthermore, the influence factors of specific common complications were analyzed. The univariate analysis showed that patients with extremely severe COPD had a significantly increased rate of atelectasis compared to patients with moderate $(\mathrm{OR}=10.340, \mathrm{P}=0.017)$ or severe $(\mathrm{OR}=7.884, \mathrm{P}=0.005)$ COPD. Also, patients who received VATS lobectomy had a significantly higher atelectasis rate than those who received VATS sublobar resections $(\mathrm{P}=0.049)$. Based on the multivariate logistics regression analysis of atelectasis, we found that the grades of COPD (moderate, $\mathrm{P}=0.029$; severe, $\mathrm{P}=0.028$; or extremely severe, $\mathrm{P}=0.019$ ) and the surgical procedure (lobectomy or sublobar resection, $\mathrm{P}=0.043$ ) were independent risk factors for atelectasis postoperatively (Table 4). None of the other RCs showed a correlation with clinical parameters.

\section{Influence of the severity of COPD on perioperative factors}

The impact of perioperative factors, including the surgical and anesthesia time, volume of intraoperative bleeding, length of stay, and duration and volume of drainage, for moderate or severe/extremely severe COPD patients is shown in Table S1. A lower incidence of intraoperative bleeding volume was observed in the moderate COPD group compared with the severe/extremely severe COPD group $(\mathrm{P}=0.017)$. There were no differences in the other perioperative factors between the moderate and severe/ extremely severe COPD groups.

\section{Discussion}

Our study examined the in-hospital postoperative complications in primary lung cancer patients with moderate to extremely severe COPD at our center. The results indicated that COPD grades and surgical treatments had profound impact on the postoperative outcomes. In total, 46 (33\%) of the 138 patients experienced postoperative complications. Previous studies have reported a postoperative pulmonary complications frequency of $10-40 \%$ in cancer patients undergoing VATS lobectomy (10-13), our study showed the postoperative complication frequency in lung cancer patients with moderate/severe COPD undergoing VATS surgery is relatively higher than common lung cancer patients. In the present study, the most common postoperative complication was atelectasis $(13 / 138$, $9 \%)$, followed by pulmonary infection $(11 / 138,8 \%)$, pleural effusion $(9 / 138,7 \%)$, respiratory failure $(4 / 138,3 \%)$, and chylothorax $(2 / 138,1 \%)$. Moreover, there was a difference in the RC rates between extremely severe COPD patients and moderate/severe COPD patients $(\mathrm{P}=0.03)$, which was 
Table 2 Univariate analysis of overall, respiratory, and cardiac system complications stratified by clinical characteristics

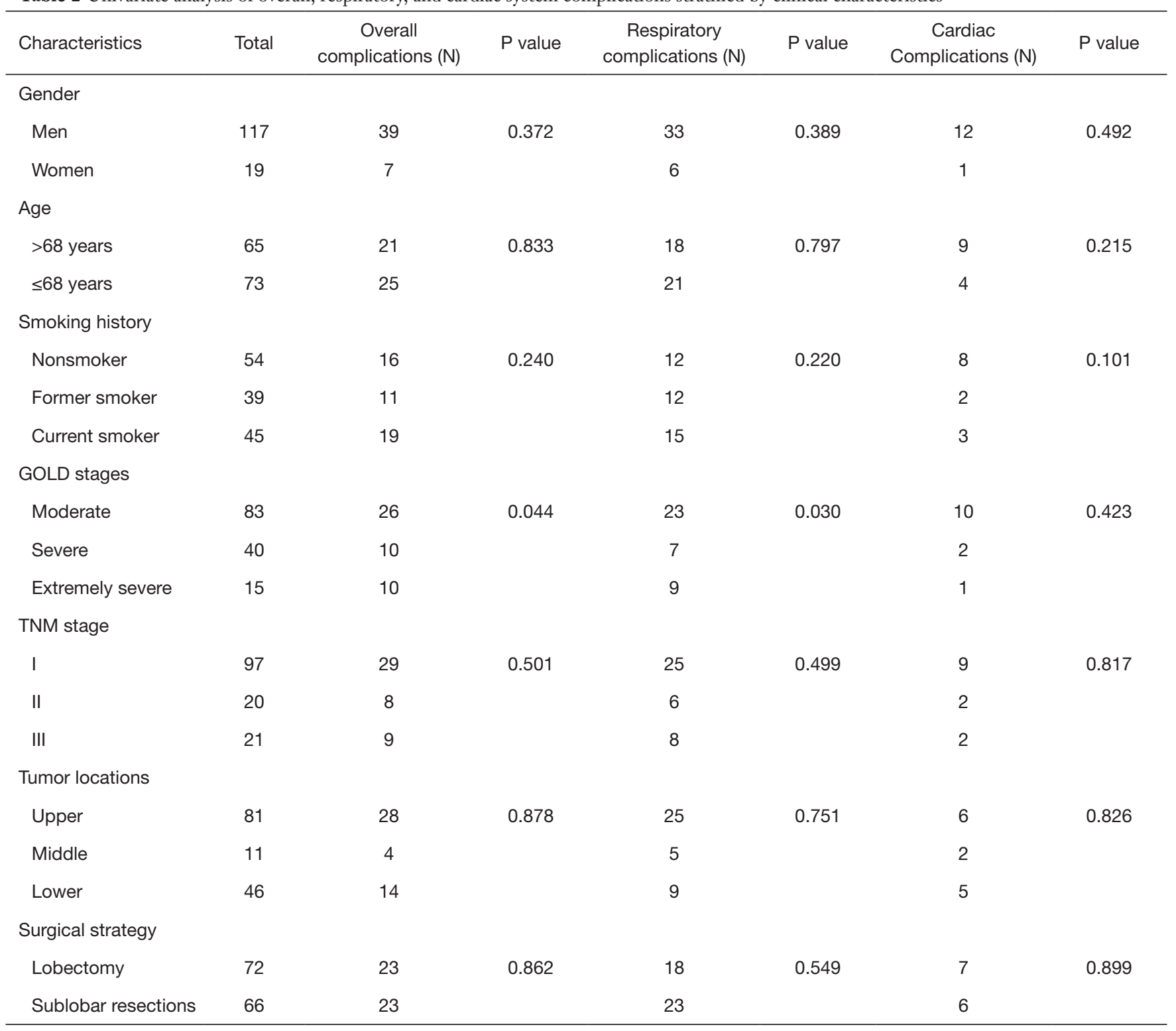

COPD, chronic obstructed pulmonary diseases; GOLD, Global Initiative for Chronic Obstructive Lung Disease; TMN, tumor-node-metastasis.

mainly attributable to parenchymal air leak or atelectasis, which was the most frequent complication in this cohort.

We sought to identify the independent risk factors that were significantly associated with postoperative complications following VATS. In our study, the rates of postoperative complication were significantly increased with a higher grade of COPD based on the GOLD criteria determined by univariate analysis. Meanwhile, the COPD grades were an independent risk factor for the postoperative $\mathrm{RCs}(\mathrm{P}=0.024)$ in multivariate analysis, which was consistent with previous studies (10). But our finding that $\mathrm{FEV} 1 \%$ or $\mathrm{FVC} \%$ predicted was not predictive of postoperative complications in VATS which was supported by Berry et al. (14). Moreover, we found that the grades of COPD and surgical procedures were 2 independent risk factors for postoperative atelectasis. This may be due to the poor quality of lung parenchyma and weakened elastic retraction of emphysema, thereby delaying lung tissue recovery (15). Postoperative atelectasis can be treated with airway clearance techniques, including postural drainage 
A

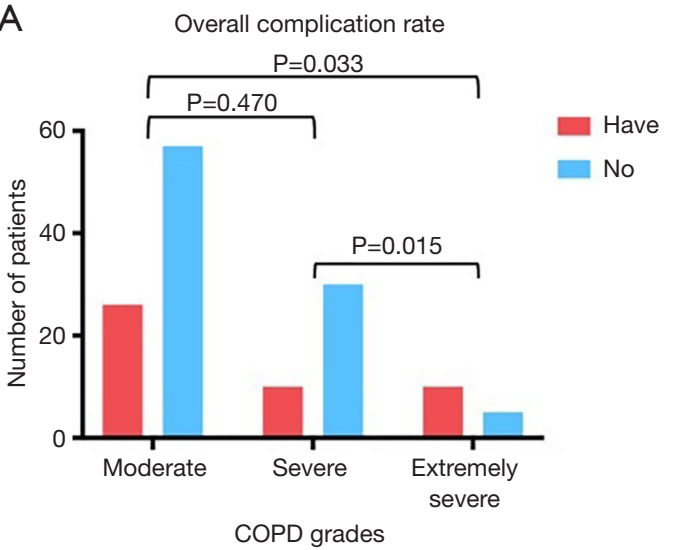

B Respiratory complication rate

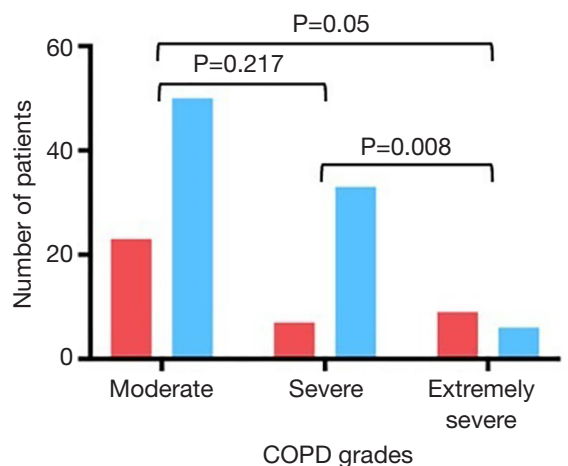

Figure 2 The multiple comparison of overall and respiratory complication rates between multiple GOLD stages. (A) The overall complication rate. Significantly higher overall complication rates occurred in extremely severe COPD patients compared to moderate $(\mathrm{OR}=4.550, \mathrm{P}=0.033)$ and severe grade $(\mathrm{OR}=5.910, \mathrm{P}=0.015)$ COPD patients. (B) The respiratory complication rate. Significant higher respiratory complication rates occurred in extremely severe COPD patients compared to moderate $(\mathrm{OR}=3.857, \mathrm{P}=0.050)$ and severe grade $(\mathrm{OR}=7.062, \mathrm{P}=0.008)$ subgroups. COPD, chronic obstructed pulmonary diseases; GOLD, Global Initiative for Chronic Obstructive Lung Disease; OR, odds ratio.

Table 3 Multivariate regression analysis of respiratory complications among primary lung cancer patients with moderate to extremely severe COPD

\begin{tabular}{|c|c|c|c|c|c|}
\hline Characteristics & $\mathrm{B}^{\star}$ & $P$ value & OR & \multicolumn{2}{|c|}{$95 \% \mathrm{Cl}$} \\
\hline Constants & 1.270 & 0.000 & 0.281 & & \\
\hline \multicolumn{6}{|l|}{ GOLD stages } \\
\hline Moderate (reference) & & 0.027 & & & \\
\hline Extremely severe & 1.453 & 0.030 & 4.275 & 1.154 & 15.843 \\
\hline
\end{tabular}

${ }^{*} \mathrm{~B}$, regression coefficients. COPD, chronic obstructed pulmonary diseases; OR, odds ratio; GOLD, Global Initiative for Chronic Obstructive Lung Disease.

Table 4 Univariate and multivariate analysis for postoperative atelectasis among primary lung cancer patients with moderate to extremely severe COPD

\begin{tabular}{|c|c|c|c|c|}
\hline Variables & $\begin{array}{c}\text { Univariate analysis } \\
\mathrm{P} \text { value }\end{array}$ & \multicolumn{3}{|c|}{ Multivariate analysis } \\
\hline GOLD stages & 0.002 & & & \\
\hline Moderate (reference) & & & & 0.029 \\
\hline Severe & 0.818 & 1.755 & $5.786(1.071-31.264)$ & 0.028 \\
\hline Surgical strategy & 0.049 & & & \\
\hline \multicolumn{5}{|c|}{ Sublobar resections (reference) } \\
\hline Lobectomy & & 1.214 & $0.189(0.037-0.949)$ & 0.043 \\
\hline
\end{tabular}

COPD, chronic obstructed pulmonary diseases; OR, odds ratio; GOLD, Global Initiative for Chronic Obstructive Lung Disease. 
and coughing, and bronchial suction using bronchoscopy or a tracheal catheter inserted through cricothyroid ligament as needed (16). With regards to the impact of surgical procedures, lobectomy has higher rates of air leak than does sublobar resection, which may be attributable to the radical anatomical resection. This leads to greater surgical soft tissue trauma and markedly longer healing times compared to the "compromise" of nonradical sublobar resection.

Furthermore, we believed that patients undergoing VATS lung cancer resection who develop postoperative pulmonary complications need more physiotherapy, including sputum clearance and lung expansion. For instance, in our study, 43 patients $(31 \%)$ received BiPAP mode noninvasive mechanical ventilation under poor conditions of pulmonary ventilation postoperatively, and 18 patients (13\%) received sputum suction via fiberoptic bronchoscope. BiPAP may be considered as an alternative treatment for postoperative respiratory failure in patients that undergo primary lung cancer resection and may significantly improve respiratory parameters and oxygenation from baseline values $(17,18)$. Pulmonary rehabilitation has been shown to improve the lung function recovery rate following surgery and may decrease postoperative pulmonary complications (19). Pulmonary infection or pneumonia was the second most common complication in our study, and should also thus not be ignored, as it is the leading causes of postoperative morbidity and death (20), and patients with COPD had higher rates of postoperative pneumonia (21). A Cochrane systematic review of 7 randomized controlled trials emphasized that treatment with a combination of corticosteroids/long-acting beta 2-agonists (LABA) (fluticasone and salmeterol) increases the risk of pneumonia in patients with COPD (22). Treatment of postoperative pulmonary infection starts with microbiological studies of respiratory samples followed by a determination of the presence of sepsis and risk factors for multidrug-resistant pathogens. Subsequently, adequate selection of antibiotics and the escalation or de-escalation principle is required (23).

From a clinical point of view, due to limited lung function, the presence of COPD in primary lung cancer may increase the risk of complications during and after lung surgery. Previous study showed that lung cancer patients with COPD have a worse prognosis than those without COPD (24). The advent of VATS techniques provides a safe alternative for individuals with poor physical performance status (PS) who may have potential high rates of postoperative complications $(25,26)$. This minimally invasive surgery reduces the adverse effects on lung function because it limits damage to the chest wall and causes minimal trauma to the respiratory muscles $(27,28)$. Partial resection through VATS may still have therapeutic benefits. If VATS can be selected, some high-risk patients (elderly and/or poor lung function) who are not suitable for thoracotomy can be considered candidates for surgery $(29,30)$. Yet, thoracic surgeons still must face the problem of the surgical approach under VATS. For normal patients with stage I NSCLC, anatomic lobectomy is better than sublobar resection (segmentectomy or wedge resection) (31). However, many patients with COPD have impaired lung function, which may affect their ability to tolerate surgery. The local recurrence rate of sublobar resection is 3 times higher than that of lobectomy (31) and is an inferior approach for any patient with early-stage disease. Thus, it is necessary to further investigate the optimal candidates with COPD who are suitable for VATS lobectomy.

VATS pulmonary surgery is technically feasible and safe in selected primary lung cancer patients with moderate to extremely severe COPD; in our study, all surgeries were performed through VATS without conversion to thoracotomy, and no patients died during hospitalization. The surgical approach is dependent on an optimal perioperative management, which may include appropriate medical therapy and preoperative and postoperative pulmonary rehabilitation (32), along with series of presurgical evaluations $(7,33)$ such as the use of pulmonary function studies, cardiopulmonary exercise testing, and nuclear perfusion scanning and intraoperative management such as ischemic preconditioning (IPC) $(34,35)$ , which enable thoracic surgeons to assess pulmonary risk and select patient for lung resection. When formulating surgical strategies, all cases must be individualized and analyzed from different perspectives for the indications and contraindications of VATS lobectomy for the treatment of lung cancer.

However, our study was limited by its retrospective design, the number of patients is small, and the control group is lacking for comparison. Also, the number of cases of positive postoperative complications was not sufficiently large to reach persuasive statistical power, and there were no standard criteria for identifying and recording the severity of complications. Future studies should use well-validated scales to assess postoperative complications.

\section{Conclusions}

In summary, our experience showed that the aggravation 
of COPD is associated with an increased incidence of postoperative complications, especially atelectasis. For patients with moderate to severe COPD, careful perioperative evaluation should be performed to determine the indicators that influence the surgical choice between lobectomy and sublobar resection.

\section{Acknowledgments}

The authors appreciate the academic support from AME Lung Cancer Collaborative Group, and thank professors Hiroaki Kuroda (Aichi Cancer Center Hospital, Japan), Teruaki Mizobuchi (Chibaken Saiseikai Narashino Hospital, Japan) and Davor Stamenovic (University of Mainz, Germany) for their critical comments and valuable advice on this study.

Funding: This study was supported by funding from the National Key R\&D Program of China (grant no. 2017YFC0907903 to Jun Liu) and the "Summit (Dengfeng) Plan" Talent Training Program of the First Affiliated Hospital of Guangzhou Medical University (grant number 34001009 to Jun Liu).

\section{Footnote}

Reporting Checklist: The authors have completed the STROBE reporting checklist. Available at https://dx.doi. org/10.21037/tlcr-21-449

Data Sharing Statement: Available at https://dx.doi. org/10.21037/tlcr-21-449

Conflicts of Interest: All authors have completed the ICMJE uniform disclosure form (available at https://dx.doi. org/10.21037/tlcr-21-449). The authors have no conflicts of interest to declare.

Ethical Statement: The authors are accountable for all aspects of the work in ensuring that questions related to the accuracy or integrity of any part of the work are appropriately investigated and resolved. All procedures performed in this study involving human participants were in accordance with the Declaration of Helsinki (as revised in 2013). The study was approved by the ethics committee of the First Affiliated Hospital of Guangzhou Medical University (18-041/1616). The requirement for informed consent from each patient was waived due to the retrospective nature of this analysis.
Open Access Statement: This is an Open Access article distributed in accordance with the Creative Commons Attribution-NonCommercial-NoDerivs 4.0 International License (CC BY-NC-ND 4.0), which permits the noncommercial replication and distribution of the article with the strict proviso that no changes or edits are made and the original work is properly cited (including links to both the formal publication through the relevant DOI and the license). See: https://creativecommons.org/licenses/by-nc-nd/4.0/.

\section{References}

1. Jemal A, Bray F, Center MM, et al. Global cancer statistics. CA Cancer J Clin 2011;61:69-90.

2. Qaseem A, Wilt TJ, Weinberger SE, et al. Diagnosis and management of stable chronic obstructive pulmonary disease: a clinical practice guideline update from the American College of Physicians, American College of Chest Physicians, American Thoracic Society, and European Respiratory Society. Ann Intern Med 2011;155:179-91.

3. de Torres JP, Marín JM, Casanova C, et al. Lung cancer in patients with chronic obstructive pulmonary disease-incidence and predicting factors. Am J Respir Crit Care Med 2011;184:913-9.

4. de Torres JP, Bastarrika G, Wisnivesky JP, et al. Assessing the relationship between lung cancer risk and emphysema detected on low-dose CT of the chest. Chest 2007;132:1932-8.

5. Zhanhong $X$, Chengzhi $Z$, Yinyin Q, et al. Diagnosis and treatment strategy for advanced severe lung cancer. Chinese Journal of Practical Internal Medicine 2019;39:416-9.

6. Yingying Q, Chengzhi Z, Xiaoxian Z, et al. Clinical Research of Patients with Primary Bronchogenic Carcinoma Complicated with Chronic Obstructive Pulmonary Disease. Chin J Respir Crit Care Med 2013:65-8.

7. Colice GL, Shafazand S, Griffin JP, et al. Physiologic evaluation of the patient with lung cancer being considered for resectional surgery: ACCP evidencedbased clinical practice guidelines (2nd edition). Chest 2007;132:161s-77s.

8. Raviv S, Hawkins KA, DeCamp MM Jr, et al. Lung cancer in chronic obstructive pulmonary disease: enhancing surgical options and outcomes. Am J Respir Crit Care Med 2011;183:1138-46.

9. Rashid OM, Takabe K. Are video-assisted thoracoscopic surgery (VATS) and robotic video-assisted thoracic surgery 
(RVATS) for pulmonary resection ready for prime time? J Thorac Dis 2012;4:341-2.

10. Agostini PJ, Lugg ST, Adams K, et al. Risk factors and short-term outcomes of postoperative pulmonary complications after VATS lobectomy. J Cardiothorac Surg 2018;13:28.

11. Yang J, Xia Y, Yang Y, et al. Risk factors for major adverse events of video-assisted thoracic surgery lobectomy for lung cancer. Int J Med Sci 2014;11:863-9.

12. Wang Z, Zhang J, Cheng Z, et al. Factors affecting major morbidity after video-assisted thoracic surgery for lung cancer. J Surg Res 2014;192:628-34.

13. Paul S, Sedrakyan A, Chiu YL, et al. Outcomes after lobectomy using thoracoscopy vs thoracotomy: a comparative effectiveness analysis utilizing the Nationwide Inpatient Sample database. Eur J Cardiothorac Surg 2013;43:813-7.

14. Berry MF, Villamizar-Ortiz NR, Tong BC, et al. Pulmonary function tests do not predict pulmonary complications after thoracoscopic lobectomy. Ann Thorac Surg 2010;89:1044-51; discussion 51-2.

15. Cui F, Liu J, Shao W, et al. Thoracoscopic minimally invasive surgery for non-small cell lung cancer in patients with chronic obstructive pulmonary disease. J Thorac Dis 2013:S260-6.

16. Hoshikawa Y, Tochii D. Postoperative Atelectasis and Pneumonia after General Thoracic Surgery. Kyobu Geka 2017;70:649-55.

17. Li P, Lai Y, Zhou K, et al. Can Perioperative Oscillating Positive Expiratory Pressure Practice Enhance Recovery in Lung Cancer Patients Undergoing Thorascopic Lobectomy? Zhongguo Fei Ai Za Zhi 2018;21:890-5.

18. Mas A, Masip J. Noninvasive ventilation in acute respiratory failure. Int J Chron Obstruct Pulmon Dis 2014;9:837-52.

19. Kehlet H. Multimodal approach to control postoperative pathophysiology and rehabilitation. Br J Anaesth 1997;78:606-17.

20. Serpa Neto A, Hemmes SN, Barbas CS, et al. Incidence of mortality and morbidity related to postoperative lung injury in patients who have undergone abdominal or thoracic surgery: a systematic review and meta-analysis. Lancet Respir Med 2014;2:1007-15.

21. Sekine Y, Yamada Y, Chiyo M, et al. Association of chronic obstructive pulmonary disease and tumor recurrence in patients with stage IA lung cancer after complete resection. Ann Thorac Surg 2007;84:946-50.

22. Nannini LJ, Poole P, Milan SJ, et al. Combined corticosteroid and long-acting beta(2)-agonist in one inhaler versus inhaled corticosteroids alone for chronic obstructive pulmonary disease. Cochrane Database Syst Rev 2013;2013:CD006826.

23. Gautam SS, O'Toole RF. Convergence in the Epidemiology and Pathogenesis of COPD and Pneumonia. Copd 2016;13:790-8.

24. Rabe KF, Hurd S, Anzueto A, et al. Global strategy for the diagnosis, management, and prevention of chronic obstructive pulmonary disease: GOLD executive summary. Am J Respir Crit Care Med 2007;176:532-55.

25. Swanson SJ, Herndon JE, 2nd, D'Amico TA, et al. Videoassisted thoracic surgery lobectomy: report of CALGB 39802--a prospective, multi-institution feasibility study. J Clin Oncol 2007;25:4993-7.

26. Demmy TL, Curtis JJ. Minimally invasive lobectomy directed toward frail and high-risk patients: a case-control study. Ann Thorac Surg 1999;68:194-200.

27. Vannucci F, Gonzalez-Rivas D. Is VATS lobectomy standard of care for operable non-small cell lung cancer? Lung Cancer 2016;100:114-9.

28. Nagahiro I, Andou A, Aoe M, et al. Pulmonary function, postoperative pain, and serum cytokine level after lobectomy: a comparison of VATS and conventional procedure. Ann Thorac Surg 2001;72:362-5.

29. Long H, Tan Q, Luo Q, et al. Thoracoscopic Surgery Versus Thoracotomy for Lung Cancer: Short-Term Outcomes of a Randomized Trial. Ann Thorac Surg 2018;105:386-92.

30. Stamenovic D, Messerschmidt A, Schneider T. Surgery for lung tumors in the elderly: A retrospective cohort study on the influence of advanced age (over 80 years) on the development of complications by using a multivariate risk model. Int J Surg 2018;52:141-8.

31. Ginsberg RJ, Rubinstein LV. Randomized trial of lobectomy versus limited resection for T1 N0 non-small cell lung cancer. Lung Cancer Study Group. Ann Thorac Surg 1995;60:615-22; discussion 622-3.

32. Sanchez-Lorente D, Navarro-Ripoll R, Guzman R, et al. Prehabilitation in thoracic surgery. J Thorac Dis 2018;10:S2593-600.

33. Brunelli A, Charloux A, Bolliger CT, et al. The European Respiratory Society and European Society of Thoracic Surgeons clinical guidelines for evaluating fitness for radical treatment (surgery and chemoradiotherapy) in patients with lung cancer. Eur J Cardiothorac Surg 2009;36:181-4.

34. Zhang W, Chen M, Li H, et al. Hypoxia preconditioning 
attenuates lung injury after thoracoscopic lobectomy in patients with lung cancer: a prospective randomized controlled trial. BMC Anesthesiol 2019;19:209.

35. Lu GW, Yu S, Li RH, et al. Hypoxic preconditioning: a novel intrinsic cytoprotective strategy. Mol Neurobiol 2005;31:255-71.

(English Language Editor: A. Kassem)

Cite this article as: $\mathrm{Xu} \mathrm{K}$, Cai W, Zeng Y, Li J, He J, Cui F, Liu J. Video-assisted thoracoscopic surgery for primary lung cancer resections in patients with moderate to severe chronic obstructive pulmonary diseases. Transl Lung Cancer Res 2021;10(6):2603-2613. doi: 10.21037/tlcr-21-449 
Supplementary

Table S1 Influence of the severity of COPD on the surgery

\begin{tabular}{lccc}
\hline Characteristics & Moderate COPD & Severe to extremely severe COPD & P value \\
\hline Surgical time $(\mathrm{min})$ & $155.15 \pm 13.69$ & $145.62 \pm 7.585$ & 0.681 \\
Anesthesia time $(\mathrm{min})$ & $232.79 \pm 17.02$ & $231.89 \pm 9.094$ & 0.733 \\
Intraoperative bleeding $(\mathrm{ml})$ & $40.00 \pm 5.734$ & $131.09 \pm 29.29$ & 0.017 \\
Length of stay $(\mathrm{d})$ & $7.86 \pm 0.425$ & $8.68 \pm 1.11$ & 0.703 \\
Duration of drainage $(\mathrm{d})$ & $4.18 \pm 0.635$ & $4.47 \pm 0.356$ & 0.555 \\
Volume of drainage $(\mathrm{ml})$ & $936.56 \pm 132.91$ & $1,072.54 \pm 107.05$ & 0.569 \\
\hline
\end{tabular}

COPD, chronic obstructed pulmonary diseases.

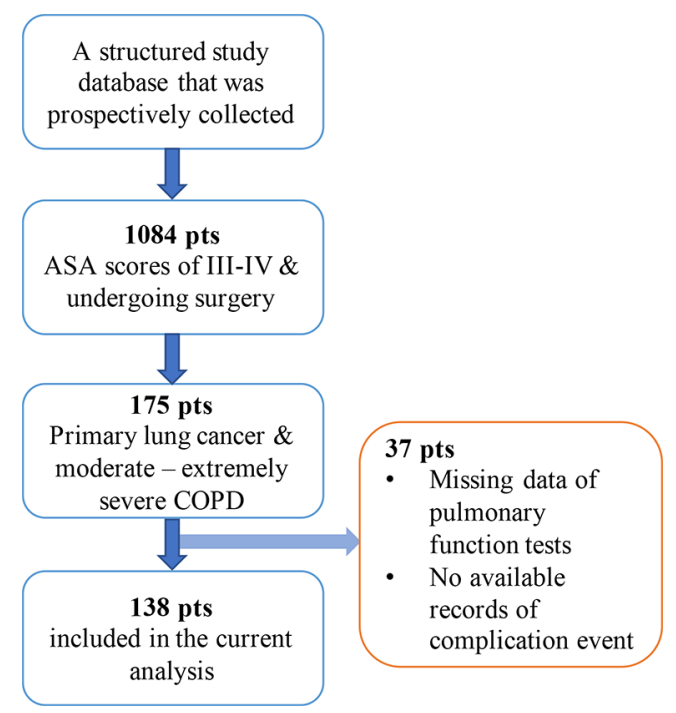

Figure S1 The flow diagram of patients' selection. 